\title{
Efeitos de sulfato de vincristine sobre os testículos de ratos albinos, tratados na fase pré-púbere ${ }^{1}$
}

\author{
Edson V.L. Veloso ${ }^{2 *}$, Lorena C.M. Figueirêdo ${ }^{2}$, Danilo J.A. Menezes², \\ Otávio B. Sousa ${ }^{2}$ e José R.S. Santos ${ }^{2}$
}

\begin{abstract}
Veloso E.V.L., Figueirêdo L.C.M., Menezes D.J.A., Sousa O.B. \& Santos J.R.S. 2018. [Effects of vincristine sulphate on albino rat testis treated in the prepuberal phase.] Efeitos de sulfato de vincristine sobre os testículos de ratos albinos, tratados na fase pré-púbere. Pesquisa Veterinária Brasileira 38(6):1217-1224. Departamento de Medicina Veterinária, Universidade Federal de Campina Grande, Avenida Universitária s/n, Jatobá, Patos, PB 58708-110, Brazil. E-mail: edsonlveloso@gmail.com

This study evaluated the vincristine sulfate effect on rat testes treated in pre pubertal stage, especially regarding the changes of Sertoli cells and germ cells. Thirty control rats and 30 rats treated with vincristine sulfate were used. The drug application occurred at 15 days of life, and euthanasia at 40,64 and 127 days of life to enable evaluation at different stages of reproductive development. Biometric measurements were performed (body and testicular weights), testicular morphometric measures (major and minor testicular axis and of seminiferous tubule and seminiferous lumen) and stereological (testicular volumes and volume densities of the tubular and testicular interstitial tissue). The biometric measurements were made on all rats in the experiment, and morphometric and stereological analysis was carried out in 200 seminiferous tubules. The results demonstrate that vincristine sulfate reduces biometric parameters such as body weight, testicular weight and the total testicular volume. Morphometric and stereological variables as diameter of the seminiferous tubules, height of the seminiferous epithelium and volume of the seminiferous tubules were also reduced. The most affected cell types were spermatogonia, late spermatids and Sertoli cells.
\end{abstract}

INDEX TERMS: Vincristine sulphate, rats, testis, prepuberal phase, chemotherapy, male gonads, lesion.

RESUMO.- Este trabalho visou avaliar os efeitos de sulfato de vincristine sobre os testículos de ratos tratados na fase pré púbere, sobretudo quanto às alterações das células de Sertoli e das células germinativas. Foram utilizados 30 animais controles e 30 tratados com sulfato de vincristine. As aplicações da droga ocorreram aos 15 dias de vida, e a eutanásia aos 40,64 e 127 dias de vida para possibilitar a avaliação em diferentes estágios de desenvolvimento reprodutivo. Foram realizadas medidas biométricas (pesos corpóreos e testiculares), medidas morfométricas testiculares, (eixos testiculares maiores e menores, diâmetros testiculares de túbulo e lúmen seminíferos, e altura do epitélio seminífero)

\footnotetext{
${ }^{1}$ Recebido em 19 de junho de 2017.

Aceito para publicação em 26 de setembro de 2017.

2 Departamento de Medicina Veterinária, Universidade Federal de Campina Grande, Avenida Universitária s/n, Santa Cecília, Patos, PB 58708-110, Brasil. Pesquisa de Mestrado com apoio CAPES/CNPq. E-mails: lorenac.m.f@hotmail.com,brilhante_sousa@yahoo.com.br, mdanayres@gmail.com,jromulosmedvet@hotmail.com; *Autor para correspondência: edsonlveloso@gmail.com
}

e estereológicas (volumes testiculares e as densidades de volume do tecido tubular e do tecido intersticial testicular). As medidas biométricas foram feitas em todos os animais do experimento, e as avaliações morfométricas e estereológicas foram realizadas em 200 túbulos seminíferos. Os resultados demonstraram que sulfato de vincristine reduz parâmetros biométricos como peso corpóreo, peso testicular e volume testicular total. Variáveis morfométricas e estereológicas como diâmetro dos túbulos seminíferos, altura do epitélio seminífero e volume dos túbulos seminíferos também foram reduzidos. Os tipos celulares mais atingidos foram as espermatogônias, espermátides tardias e células de Sertoli.

TERMOS DE INDEXAÇÃO: Sulfato de vincristine, testículos, ratos, fase pré-púbere, quimioterápico, gônadas masculinas, lesão.

\section{INTRODUÇÃO}

O sulfato de vincristine é amplamente utilizado na medicina veterinária para tratamento de diversos tipos de tumores medulares, além de ser a droga de eleição no tratamento de 
tumor venéreo transmissível (TVT) em cães (Nak et al. 2005, Rosenthal 1981). Trata-se de uma droga que atua sobre as células em processo de replicação, causando a precipitação da tubulina e impedindo a divisão celular em células normais e neoplásicas.

Assim, todas as células em processo de divisão, saudáveis ou tumorais, são alvo da ação da droga quando em processo de divisão. Estudos demonstram que esse alcalóide, que atua causando a precipitação da tubulina e impedindo a divisão celular, pode danificar alguns tecidos normais com altos níveis de proliferação celular, em especial o epitélio seminífero, células germinativas e células de Sertoli (Hodel et al. 1984, Daleck et al. 1995, Diniz et al. 1999, Vaisheva et al. 2007, Delbès et al. 2010, Martins et al. 2011).

0 presente estudo visa descrever a possível influência do sulfato de vincristine sobre a macro e a microestrutura testicular de ratos albinos na fase pré-púbere, púbere e adulta. A pesquisa identifica e descreve os danos provocados pelo quimioterápico, expressos em alterações das variáveis morfológicas testiculares, contribuindo para a realização de estudos focados no desenvolvimento de novos tratamentos incluindo novas drogas ou protocolos uma vez que será traçado um panorama dos efeitos deletérios sobre o parênquima testicular e os tipos celulares envolvidos em fases estratégicas do desenvolvimento do testículo.

\section{MATERIAL E MÉTODOS}

Comitê de Ética. Este projeto de pesquisa foi submetido ao Comitê de Ética em Pesquisa da Unidade Acadêmica de Medicina Veterinária (UAMV), Centro de Saúde e Tecnologia Rural (CSTR), Universidade Federal de Campina Grande (UFCG), Campus de Patos/PB, sendo aprovado sob o protocolo CEP 185/2014.

Obtenção dos animais. Sessenta (60) ratos Wistar machos (Rattus norvegicus albinus) oriundos do acasalamento de matrizes provenientes do biotério do Centro de Saúde e Tecnologia Rural da Universidade Federal de Campina Grande foram utilizados para avaliar os efeitos do sulfato de vincristine. Os acasalamentos ocorreram no período noturno, e na manhã do dia seguinte, foram realizados esfregaços vaginais para averiguar a presença de espermatozóides, atestando assim a cobertura. Esse dia foi considerado o dia 0 de gestação.

Padronização da dosagem do sulfato de vincristine. Trinta animais receberam dose de $0,05 \mathrm{mg} / \mathrm{kg}$ de peso vivo de sulfato de vincristine por via intraperitoneal. Trinta animais foram utilizados como grupo controle recebendo solução salina na mesma dose do quimioterápico.

Formação dos grupos experimentais e controles. 0 grupo controle (GC) recebeu solução salina por via intraperitoneal aos 15 dias de idade, na mesma dose empregada no grupo vincristine (GV). Objetivou-se com isso simular as condições de manipulação do grupo tratado, efetuando-se os mesmos procedimentos em todos os grupos. Os animais do grupo GV receberam sulfato de vincristine em dose única por via intraperitoneal de $0,05 \mathrm{mg} / \mathrm{kg}$ de peso vivo aos 15 dias idade (Hodel et al. 1984). 0 dia da administração da droga foi escolhido com base no tempo de desenvolvimento da barreira hematotesticular e na maturação das células de Sertoli, visto que até $18^{\circ}$ dia de vida essas células ainda não estão completamente maduras e a barreira hematotesticular ainda está em formação (Clegg 1960, Russell et al. 1990).

Os grupos GC e GV foram divididos em três subgrupos de dez animais cada, de acordo com as idades em que foram eutanasiados:
40 dias de vida (subgrupos $\mathrm{GC}_{40}$ e $\mathrm{GV}_{40}$ ); 64 dias de vida (subgrupos $\mathrm{GC}_{64}$ e $\mathrm{GV}_{64}$ ) e 127 dias de vida (subgrupos $\mathrm{GC}_{127}$ e $\mathrm{GV}_{127}$ ).

Os grupos foram designados por índices numéricos de acordo as idades em que foram submetidos ao sacrifício. As idades foram escolhidas com base em fases importantes do desenvolvimento do aparelho reprodutor masculino da espécie, segundo Clegg (1960), onde, os ratos de 40 dias são considerados pré púbere, com 64 dias são púberes, mas não sexualmente maduros, e com 127 dias são sexualmente maduros. Nas idades especificadas, os animais foram anestesiados com Tiopental Sódico (89mg/kg de peso corpóreo) segundo Brilhante et al. (2012), seguida de remoção de ambos os testículos.

Coleta e processamento das amostras. Nas idades especificadas, os ratos foram pesados e submetidos à eutanásia. Os testículos foram removidos e pesados em balança semi-analítica de precisão BG 1000 Gehaka $^{\circledR}$. Os eixos maiores e menores foram mensurados com auxílio de um paquímetro MITUTOYO. A estereologia foi realizada por meio da medição do volume testicular pelo método de Scherle (1970).

As amostras foram processadas por imersão em Bouin e após 30 minutos foram hemisseccionadas e as hemissecções retornaram a solução de Bouin permanecendo por 24 horas. Após a fixação, as amostras foram no Laboratório de Patologia Animal (LPA) do Hospital Veterinário (HV) do Centro de Saúde e Tecnologia Rural (CSTR), Universidade Federal de Campina Grande (UFCG), Campus de Patos, Paraíba, em processo semelhante ao realizado por Michalany (1998).

Foram obtidas secções de $5 \mu \mathrm{m}$ de cada testículo (direito/esquerdo) por meio do micrótomo manual LEICA RM2125 RT e navalhas descartáveis Easy Path DURAEDGE. Uma secção do testículo direito e outra do esquerdo de cada animal foi corada com Hematoxilina e Eosina (HE), possibilitando a identificação dos tipos celulares e a realização da avaliação morfométrica e estereológica do parênquima testicular.

Biometria, morfometria, estereologia e análise histológica. A análise biométrica compreendeu a pesagem dos animais do dia seguinte ao nascimento até o momento da eutanásia, a determinação do peso testicular absoluto (em grama), do peso testicular relativo segundo a fórmula (peso testicular absoluto/100g de peso vivo), e dos eixos testiculares maiores e menores. A análise biométrica incluiu a mensuração do volume testicular segundo o método de Scherle (1970), o qual consiste em imergir o órgão suspenso por um fio cirúrgico agulhado em recipiente contendo solução salina isotônica. Utiliza-se uma balança semi analítica tarada e o valor deve ser registrado e descontado o peso do fio agulhado para obter o volume do órgão (Mandarim-de-Lacerda 1995). A gravidade específica é a razão entre a densidade do órgão avaliado e a densidade da substancia de referência (água), segundo Moura et al. (2006), a gravidade específica do testículo do rato deve ser considerada como igual a da água 1.0 (Russell \& França 1995). Desta forma, o volume testicular total foi obtido a partir da seguinte fórmula: Volume $=$ Densidade $\mathrm{x}$ Massa.

A média do volume testicular total de cada grupo foi obtida por meio do calculo das médias aritméticas dos volumes dos dois testículos de cada animal dos seus respectivos grupos controles e experimentais.

A avaliação morfométrica foi realizada com auxílio do software Image-Pro Express 6.0 em computador acoplado ao microscópio binocular de luz Olympus BX40 com objetiva de 20x. Foram mensurados de forma aleatória 200 túbulos seminíferos em corte transversal por animal (100 em cada testículo). Os cortes testiculares foram totalmente e sequencialmente varridos, evitando-se a análise em duplicidade de uma mesma área. Mensurou-se o diâmetro dos túbulos, diâmetro do lúmen tubular, altura do epitélio seminífero, 
área do túbulo, do lúmen e do epitélio seminífero, e eixos maiores (diâmetro) e menores dos túbulos seminíferos. Todos os parâmetros foram mensurados de forma individual e em seguida calculada a média ponderada de cada grupo.

Microscopicamente a estereologia foi realizada em cortes dos testículos esquerdos e direito, um corte de cada testículo (esquerdo e direito) foi submetido à análise da densidade de volume (Vv) tubular e do tecido intersticial do parênquima testicular. As variáveis estereológicas de densidade de volume (Vv) foram obtidas por meio da contagem dos pontos por alocação sistemática e aleatória das imagens obtidas através do software IMAGE-PRO EXPRESS $6.0 \mathrm{em}$ computador acoplado em microscópio binocular de luz Olympus BX40no aumento de 20x e posteriormente empregada no software Image J para a contagem de pontos, totalizando 840 pontos por testículo (Gundersen et al. 1988, Mandarim-de-Lacerda 1995).

A densidade dos tecidos intersticiais e dos túbulos seminíferos em $\mathrm{mm}^{3}$ foram calculadas a partir do percentual obtido na densidade de volume (Vv) de cada tecido, segundo Miraglia \& Hayashi (1993). Os volumes tubulares e intersticiais médios por animal também foram obtidos através do calculo com os dados obtidos para o volume total dos testículos direito e esquerdo.

A densidade de comprimento dos túbulos seminíferos (Lv) foi obtida utilizando a fórmula $\mathrm{Lv}=2 \mathrm{Q}$ a descrita por Gundersen et al. (1988), sendo Qa a somatória das secções tubulares existentes na área teste gravada em escala de $1 \mathrm{~mm}$ e intervalos do sistema métrico de $10 \mu \mathrm{m}$. Desta forma Qa $=\sum$ perfis/At.

Os tipos celulares básicos da linhagem germinativa e as células de Sertoli tiveram suas frequências calculadas por 100 secções tubulares por animal analisadas sob objetiva de 100x utilizando critérios estabelecidos por Leblond \& Clermont (1952) e complementados por Russell et al. (1990). Espermatogônias tipo A, tipo B, intermediária, espermatócitos primários, espermátides jovens, espermátides tardias e células de Sertoli foram observadas.

Análise estatística. Os dados foram avaliados pelo teste não paramétrico "U" de Mann Whitney. Os resultados foram considerados significativos quando $\mathrm{p} \leq 0,05$ e muito significativos quando $\mathrm{p} \leq 0,01$. A análise estatística foi realizada com o auxílio do software Bioestat 5.0. Utilizou-se letras iguais para valores não significativos quando $\mathrm{p}>0,05$; letras diferentes para valores considerados significativos $(p \leq 0,05)$ e os valores muito significativos $(p \leq 0,01)$ foram marcados com um asterisco “*”.

\section{RESULTADOS E DISCUSSÃO}

Os resultados foram obtidos com base na média aritmética dos testículos (direito e esquerdo) de cada animal e, por conseguinte, de cada grupo (40, 64 e 127 dias). Os dados foram apresentados em quadros contendo três grupos tratados com sulfato de vincristine e seus respectivos controles.

As variáveis Biométricas (Quadro 1) incluíram peso corpóreo, peso testicular absoluto, peso testicular relativo, volume testicular total, eixo testicular maior e eixo testicular menor.

As médias dos pesos corpóreos dos animais nos grupos $\mathrm{GV}_{127}$ e $\mathrm{GV}_{64}$ não diferiram estatisticamente ( $\left.\mathrm{p}>0,05\right)$ quando comparados aos seus controles respectivos, embora tenha havido redução percentual de 8,3\% no grupo tratado de 127 dias e de 1,39\% no grupo tratado de 64 dias. Porém, houve redução muito significativa $(\mathrm{p} \leq 0,01)$ na média de peso corpóreo dos animais do grupo $\mathrm{GV}_{40}$ quando comparado ao controle de mesma idade, com redução percentual de 14,49\%.

Os pesos testiculares absolutos e relativos apresentaram tendência de diminuição, estando em conformidade com outros estudos (Rosenthal 1981). Vale salientar que em todos os grupos experimentais $\left(\mathrm{GV}_{127}, \mathrm{GV}_{64} \mathrm{eGV}_{40}\right)$ houve reduções muito significativas $(\mathrm{p} \leq 0,01)$. 0 peso testicular absoluto reduziu $47,05 \%$ no grupo $\mathrm{GV}_{127}$ quando comparado ao controle de mesma idade, já nos grupos $\mathrm{GV}_{64}$ e $\mathrm{GV}_{40}$ houve reduções de $21,88 \%$ e $29,32 \%$ respectivamente. $O$ peso testicular relativo reduziu $42,26 \%$ no grupo $\mathrm{GV}_{127}$ quando comparado ao controle de mesma idade, já nos grupos $\mathrm{GV}_{64}$ e $\mathrm{GV}_{40}$ houve reduções de 20,12\% e 17,29\% respectivamente.

A redução do peso corpóreo, peso testicular assim como das demais variáveis estudadas possui relação dose dependente na maioria das drogas, ademais, o peso testicular é considerado uma variável importante na avaliação dos níveis de perda celular do epitélio seminífero (Hacker-Klom et al. 1986, Bordallo et al. 2001, Howell \& Shalet 2001). Todos os grupos experimentais apresentaram reduções muito significativas $(\mathrm{p} \leq 0,01)$ dos pesos testiculares absolutos e relativos quando comparado a seus referentes controles.

Os volumes testiculares totais acompanharam a tendência de redução observada nas demais variáveis biométricas. Os animais de grupo $\mathrm{GV}_{127}$ mostraram reduções muito significativas $(\mathrm{p} \leq 0,01)$ em comparação com o grupo $\mathrm{GC}_{127}$ ' mostrando que o quimioterápico demonstra seus efeitos citotóxicos no volume do testículo de forma tardia. Os animais

Quadro 1. Peso corpóreo (PC), peso testicular absoluto (PTA), peso testicular relativo (PTR), volume testicular total (VTT), eixo testicular maior (ETMA), eixo testicular menor (ETME) e os respectivos desvios padrões ( \pm DP) em grupos de ratos albinos controles (GC) e tratados (GV) de 40, 64 e 127 dias de idade $\left(G_{40}, G V_{40}, G C_{64}, G V_{64}, G C_{127}\right.$ e GV $\left.G_{127}\right)$

\begin{tabular}{|c|c|c|c|c|c|c|c|c|c|c|c|c|}
\hline \multicolumn{13}{|c|}{ Grupos } \\
\hline & GC-127 & $\pm \mathrm{DP}$ & GV-127 & $\pm \mathrm{DP}$ & GC-64 & $\pm \mathrm{DP}$ & GV-64 & $\pm \mathrm{DP}$ & GC-40 & $\pm \mathrm{DP}$ & GV-40 & $\pm \mathrm{DP}$ \\
\hline PC (g) & $308,7 \mathrm{a}$ & 27,2 & $283,0 \mathrm{a}$ & 39,8 & $228,2 \mathrm{a}$ & 17 & $225,0 a$ & 23,2 & $136,4 a^{*}$ & 9,1 & $116,6 b^{*}$ & 6,2 \\
\hline PTR (\%) & $0,59 a^{*}$ & 0,04 & $0,34 b^{*}$ & 0,05 & $0,71 a^{*}$ & 0,05 & $0,56 b^{*}$ & 0,08 & $0,51 a^{*}$ & 0,03 & $0,42 b^{*}$ & 0,04 \\
\hline VTT $\left(\mathrm{mm}^{3}\right)$ & $1657,16 a^{*}$ & 88,62 & $1081,11 b^{*}$ & 323,06 & $1450,12 \mathrm{a}$ & 131,19 & $1293,01 b$ & 109,45 & $600,16 a$ & 69,05 & $517,11 \mathrm{~b}$ & 58,55 \\
\hline $\begin{array}{l}\text { ETMA } \\
(\mathrm{mm})\end{array}$ & $17,02 a^{*}$ & 0,3 & $12,55 b^{*}$ & 1,19 & $16,88 a^{*}$ & 0,45 & $13,43 b^{*}$ & 0,82 & $16,88 a^{*}$ & 0,45 & $6,43 b^{*}$ & 0,78 \\
\hline
\end{tabular}

$$
(\mathrm{mm})
$$

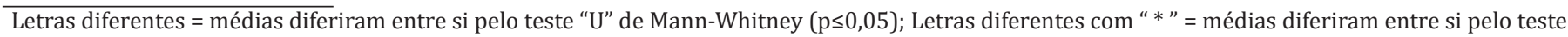
"U” de Mann-Whitney $(\mathrm{p} \leq 0,01)$; Letras iguais = médias não diferiram entre si pelo teste “ $U$ ” de Mann-Whitney $(p>0,05)$. 
dos grupos $\mathrm{GV}_{64}$ e $\mathrm{GV}_{40}$ apresentaram reduções significativas $(\mathrm{p} \leq 0,05)$, de forma que a droga afetou ativamente o volume testicular total de todos os animais do grupo experimental.

0 grupo $\mathrm{GV}_{127}$ apresentou redução de $34,76 \%$ de volume testicular total quando comparado ao grupo controle. Os grupo $\mathrm{GV}_{64}$ e $\mathrm{GV}_{40}$ reduziram 10,83\% e 13,83\% respectivamente. Os eixos testiculares maiores e menores se mostraram diminuídos nos animais de todos os grupos tratados com sulfato de vincristine quando comparados a seus respectivos controles. 0 eixo testicular maior no grupo $\mathrm{GV}_{127}$ mostrou-se diminuído 26,26\% quando comparado ao controle de mesma idade, os grupos $\mathrm{GV}_{64}$ e $\mathrm{GV}_{40}$ reduziram $20,43 \%$ e $61,90 \%$ respectivamente. 0 eixo testicular menor no grupo $\mathrm{GV}_{127}$ mostrou-se diminuído 29,36\% quando comparado ao controle de mesma idade, os grupos $\mathrm{GV}_{64}$ e $\mathrm{GV}_{40}$ reduziram $18,26 \%$ e 48,29\% respectivamente. É válido ressaltar que os eixos testiculares maiores e menores dos animais dos grupos experimentais mostraram reduções muito significativas $(\mathrm{p} \leq 0,01)$ quando comparados aos referentes controles.

As variáveis estereológicas densidade de volume dos túbulos seminíferos e do tecido intersticial, volume dos túbulos seminíferos e do tecido intersticial e densidade de comprimento estão descritas no Quadro 2.

0 presente estudo evidenciou alterações nas médias das densidades de volume dos túbulos seminíferos e do tecido intersticial testicular. Constatou-se que as densidades de volume dos túbulos seminíferos do grupo $\mathrm{GV}_{127}$ reduziu 47,59\%, já os grupos G64 e G40 tiveram discretas reduções quando comparados os grupos experimentais com seus relativos controles de 5,83\% no grupo $G_{64}$ e $6,27 \%$ no grupo $\mathrm{GV}_{40}$, porém, tais variações não diferiram de forma significativa $(p>0,05)$. Além disso, as variações numéricas entre $\mathrm{GC}_{127}$ e $\mathrm{GV}_{127}$ quanto ao volume dos túbulos seminíferos foram altamente significativas $(\mathrm{p} \leq 0,01)$ demonstrando que os efeitos deletérios de sulfato de vincristine sobre a densidade de volume dos túbulos seminíferos foram tardios incidindo de forma significativa em animais adultos (127 dias).

As densidades volumes testiculares do tecido intersticial apresentaram tendências inversas as observadas na densidade de volume dos túbulos seminíferos, pois, há relação de proporcionalidade entre as duas variáveis. Desse modo, o grupo $\mathrm{GV}_{127}$ apresentou aumento de 54,33\% demonstrando aumento relativo muito significativa $(\mathrm{p} \leq 0,01)$ da densidade de volume do tecido intersticial testicular nos animais adultos
(127 dias) tratados com sulfato de vincristine. A diferença entre os grupos tratados e controles de 40 e 64 dias foi de $13,88 \%$ e $17,70 \%$ respectivamente, não revelando diferença significativa $(\mathrm{p}>0,05)$.

Rosenthal (1981) descreveu retardo da espermatogênese em animais tratados com sulfato de vincristine, levando a crer que os efeitos deletérios da droga sobre as células da linhagem germinativa venham a ser identificados de forma tardia.

Os volumes dos túbulos seminíferos mostraram-se em tendência descendente semelhante à observada no volume testicular total, mostraram reduções muito significativa $(\mathrm{p} \leq 0,01)$ em todos os grupos experimentais $\left(\mathrm{GV}_{127}, \mathrm{GV}_{64}\right.$ e $\left.\mathrm{GV}_{40}\right)$. 0 grupo $\mathrm{GV}_{127}$ apresentou redução de $65,65 \%$, os animais do grupo $\mathrm{GV}_{64}$ reduziram $15,80 \%$, já os animais do grupo $\mathrm{GV}_{40}$ diminuíram 18,93\% quando comparados aos controles de mesma idade.

Os volumes dos tecidos intersticiais testiculares se mostraram com variações não significativas $(p>0,05)$ nos grupos $\mathrm{GV}_{64}$ e $\mathrm{GV}_{40}$ (variações de 2,55\% e 3,21\% respectivamente). Porém, o grupo $\mathrm{GV}_{127}$ demonstrou aumento significativo $(\mathrm{p} \leq 0,05)$ do volume do tecido intersticial testicular quando comparados os grupos controle $\left(\mathrm{GC}_{127}\right)$ e experimentais $\left(\mathrm{GV}_{127}\right)$, com variação de 30,02\%.

O número de perfis na área teste da densidade de comprimento tubular nos animais do $\mathrm{GV}_{127}$ aumentou $17,40 \%$ quando comparado ao controle de mesma idade, os animais do grupo $\mathrm{GV}_{64}$ aumentaram $0,8 \%$, já os animais do grupo $\mathrm{GV}_{40}$ aumentaram $0,57 \%$ o número de perfis. Os grupos $\mathrm{GV}_{40}$ e $\mathrm{GV}_{64}$ não apresentaram diferenças significativas. $O$ grupo $\mathrm{GV}_{127}$ mostrou-se diferente do grupo controle de mesma idade, sendo essa diferença muito significativa $(p \leq 0,01)$.

Segundo Eboetse et al. (2011), substâncias com efeitos deletérios para a espermatogênese podem acarretar aumento do número de perfis em uma determinada área teste, pois, dentre as alterações causadas pelas substâncias destaca-se a diminuição dos eixos dos túbulos seminíferos, dessa forma, as estruturas ocupam espaço físico menor aumentando o número de perfis computados.

As variáveis morfométricas diâmetro do túbulo seminífero, altura do epitélio seminífero, diâmetro do lúmen tubular, eixo menor do túbulo seminífero, área do túbulo seminífero, área do lúmen tubular e área do epitélio seminífero estão descritas no Quadro 3.

Quadro 2. Densidade de volume dos túbulos seminíferos (DVT), densidade de volume do tecido intersticial (DVI),

volume dos túbulos seminíferos (VT), volume tecido intersticial (VI), e densidade de comprimento (DC) com os respectivos desvios padrões ( \pm DP) em grupos de ratos albinos controles (GC) e tratados (GV) de 40, 64 e 127 dias de idade $\left(\mathrm{GC}_{40}, \mathrm{GV}_{40}, \mathrm{GC}_{64}, \mathrm{GV}_{64}, \mathrm{GC}_{127}\right.$ e $\left.\mathrm{GV}_{127}\right)$

\begin{tabular}{|c|c|c|c|c|c|c|c|c|c|c|c|c|}
\hline \multicolumn{13}{|c|}{ Grupos } \\
\hline & $\mathrm{GC}_{127}$ & $\pm \mathrm{DP}$ & $\mathrm{GV}_{127}$ & $\pm \mathrm{DP}$ & $\mathrm{GC}_{64}$ & $\pm \mathrm{DP}$ & $\mathrm{GV}_{64}$ & $\pm \mathrm{DP}$ & $\mathrm{GC}_{40}$ & $\pm \mathrm{DP}$ & $\mathrm{GV}_{40}$ & $\pm \mathrm{DP}$ \\
\hline DVT (\%) & $71,42 \mathrm{a}^{*}$ & 11,74 & $37,42 b^{*}$ & 5,62 & $73,42 a$ & 9,43 & $69,14 a$ & 8,05 & $77,42 \mathrm{a}$ & 12,59 & $72,57 a$ & 7,99 \\
\hline DVI (\%) & $28,57 a^{*}$ & 11,74 & $62,57 b^{*}$ & 5,62 & $26,57 a$ & 9,43 & $30,85 a$ & 8,05 & $22,57 a$ & 12,59 & $27,42 a$ & 7,99 \\
\hline $\mathrm{VT}\left(\mathrm{mm}^{3}\right)$ & $1185,5 a^{*}$ & 219,33 & $407,13 b^{*}$ & 141,15 & 1058,81a* & 119,75 & $891,43 b^{*}$ & 105,75 & $462,72 a^{*}$ & 77,28 & $375,1 b^{*}$ & 58,74 \\
\hline $\mathrm{VI}\left(\mathrm{mm}^{3}\right)$ & $471,6 a$ & 191,98 & $673,97 b$ & 206,88 & 391,31a & 148,69 & $401,57 a$ & 119,57 & $137,44 \mathrm{a}$ & 75,04 & $142 a$ & 44,58 \\
\hline $\mathrm{DC}\left(\mu \mathrm{m}^{2}\right)$ & $28,34 a^{*}$ & 2,28 & $34,31 b^{*}$ & 1,75 & $20,74 a$ & 2,25 & $23,67 b$ & 2,76 & 37,88a* & 2,97 & $43,69 b^{*}$ & 3,02 \\
\hline
\end{tabular}

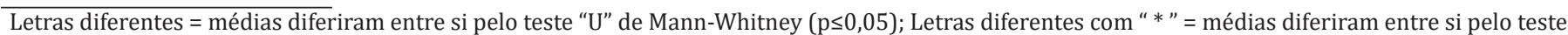

"U” de Mann-Whitney $(\mathrm{p} \leq 0,01)$; Letras iguais = médias não diferiram entre si pelo teste “U” de Mann-Whitney $(\mathrm{p}>0,05)$. 
Quadro 3. Diâmetro do túbulo seminífero (DT), altura do epitélio seminífero (ALES), diâmetro do lúmen tubular (DL), eixo menor do túbulo seminífero (EMTS), área do túbulo seminífero (ART), área do lúmen tubular (ARL) e área do epitélio seminífero (AREP) com os respectivos desvios padrões ( \pm DP) em grupos de ratos albinos controles (GC) e tratados (GV) de 40, 64 e 127 dias de idade $\left(\mathrm{GC}_{40}, \mathrm{GV}_{40}, \mathrm{GC}_{64}, \mathrm{GV}_{64}, \mathrm{GC}_{127}\right.$ e $\left.\mathrm{GV}_{127}\right)$

\begin{tabular}{cccccccccccccc}
\hline \multicolumn{10}{c}{ Grupos } \\
\hline & $\mathrm{GC}_{127}$ & $\pm \mathrm{DP}$ & $\mathrm{GV}_{127}$ & $\pm \mathrm{DP}$ & $\mathrm{GC}_{64}$ & $\pm \mathrm{DP}$ & $\mathrm{GV}_{64}$ & $\pm \mathrm{DP}$ & $\mathrm{GC}_{40}$ & $\pm \mathrm{DP}$ & $\mathrm{GV}_{40}$ & $\pm \mathrm{DP}$ \\
\hline DT $(\mu \mathrm{m})$ & $416 \mathrm{a}^{*}$ & 16,37 & $320,29 \mathrm{~b}^{*}$ & 34,67 & $421,55 \mathrm{a}^{*}$ & 10,92 & $400,94 \mathrm{~b}^{*}$ & 7,41 & $335,94 \mathrm{a}^{*}$ & 10,43 & $292,62 \mathrm{~b}^{*}$ & 9,39 \\
ALEP $(\mu \mathrm{m})$ & $125,4 \mathrm{a}^{*}$ & 6,25 & $50,75 \mathrm{~b}^{*}$ & 21,17 & $131,86 \mathrm{a}^{*}$ & 8,04 & $101,54 \mathrm{~b}^{*}$ & 3,64 & $111,81 \mathrm{a}^{*}$ & 4,44 & $87,75 \mathrm{~b}^{*}$ & 6,23 \\
DL $(\mu \mathrm{m})$ & $165,2 \mathrm{a}^{*}$ & 10,26 & $218,78 \mathrm{~b}^{*}$ & 25,02 & $157,83 \mathrm{a}^{*}$ & 14,4 & $197,86 \mathrm{~b}^{*}$ & 6,7 & $112,32 \mathrm{a}$ & 10,55 & $117,1 \mathrm{a}$ & 9,63 \\
EMTS $(\mu \mathrm{m})$ & $316,07 \mathrm{a}^{*}$ & 11,55 & $236,12 \mathrm{~b}^{*}$ & 33,45 & $324,01 \mathrm{a}$ & 15,61 & $319,77 \mathrm{a}$ & 8,14 & $261,87 \mathrm{a}^{*}$ & 18,78 & $229,99 \mathrm{~b}^{*}$ & 7,57 \\
ART $\left(\mu \mathrm{m}^{2}\right)$ & $104028,5 \mathrm{a}^{*}$ & 7210,53 & $61166,1 \mathrm{~b}^{*}$ & 14841,3 & $107211,05 \mathrm{a}$ & 6306,33 & $101443,67 \mathrm{~b}$ & 3304,8 & $69636,76 \mathrm{a}^{*}$ & 5614,82 & $53117,84 \mathrm{~b}^{*}$ & 2354,55 \\
ARL $\left(\mu \mathrm{m}^{2}\right)$ & $15331,4 \mathrm{a}^{*}$ & 1730,9 & $25396 \mathrm{~b}^{*}$ & 4143,6 & $14295,6 \mathrm{a}^{*}$ & 2980,5 & $24318,66 \mathrm{~b}^{*}$ & 1561,6 & $6840,44 \mathrm{a}$ & 1624,45 & $7702,29 \mathrm{a}$ & 1236,97 \\
AREP $\left(\mu \mathrm{m}^{2}\right)$ & $88697,0 \mathrm{a}^{*}$ & 6146,0 & $35769 \mathrm{~b}^{*}$ & 15546 & $92915,39 \mathrm{a}^{*}$ & 4329,8 & $77125,01 \mathrm{~b}^{*}$ & 2910,8 & $62796,3 \mathrm{a}^{*}$ & 4147,5 & $45415,5 \mathrm{~b}^{*}$ & 2302,2
\end{tabular}

Letras diferentes = médias diferiram entre si pelo teste " $U$ " de Mann-Whitney $(\mathrm{p} \leq 0,05)$; Letras diferentes com “* " = médias diferiram entre si pelo teste "U" de Mann-Whitney $(\mathrm{p} \leq 0,01)$; Letras iguais = médias não diferiram entre si pelo teste " $U$ " de Mann-Whitney ( $p>0,05)$.

Os diâmetros dos túbulos seminíferos revelaram-se diminuídos nos grupos experimentais. Os grupos $\mathrm{GC}_{127}$ e $\mathrm{GV}_{127}$ variaram $23 \%$, o grupo $\mathrm{GV}_{64}$ reduziu $4,88 \%$, enquanto que o grupo $\mathrm{GV}_{40}$ reduziu $12,89 \%$. É válido ressaltar que todos os animais dos grupos experimentais apresentaram reduções muito significativas $(p \leq 0,01)$ do diâmetro do túbulo seminífero quando comparados aos respectivos controles.

A altura do epitélio seminífero revelou-se reduzida em todos os animais dos grupos experimentais, tais reduções foram altamente significativas ( $\mathrm{p} \leq 0,01)$. 0 grupo $\mathrm{GV}_{127}$ diminuiu $59,52 \%$, o grupo $\mathrm{GV}_{64}$ reduziu $22,99 \%$, já os animais do grupo $\mathrm{GV}_{40}$ reduziram $21,51 \%$.

As médias dos diâmetros dos lumens dos túbulos seminíferos revelaram-se aumentadas nos animais dos grupos experimentais de $64\left(\mathrm{GV}_{64}\right)$ e $127\left(\mathrm{GV}_{127}\right)$ dias. As médias desses dois grupos apresentaram diferenças muito significativas $(p \leq 0,01)$, em contrapartida, não houve diferenças significativas $(p>0,05)$ no grupo de 40 dias quando comparadas as médias do grupo experimental e do controle.

A média de diâmetro do lúmen do túbulo seminífero do grupo $\mathrm{GV}_{127}$ aumentou $24,49 \%$, os animais do grupo $\mathrm{GV}_{64}$ tiveram médias $20,23 \%$ maiores, já os animais do grupo $\mathrm{GV}_{40}^{64}$ obtiveram médias $4,08 \%$ maiores.

As reduções no diâmetro e aumento do lúmen dos túbulos seminíferos já foram relatadas por Nasrabadi et al. (2012) e por Vaisheva et al. (2007), quando avaliaram os efeitos de sulfato de vincristine sobre as estruturas morfológicas do testículo.

As médias dos eixos menores dos túbulos seminíferos se mostraram reduzidas nos grupos experimentais $\mathrm{GV}_{127}$ e $\mathrm{GV}_{40}$, tais reduções foram muito significativas ( $\mathrm{p} \leq 0,01)$, contudo, não foram observadas diferenças ( $p>0,05)$ entre os grupos $\mathrm{GC}_{64} \mathrm{e}$ $\mathrm{GV}_{64}$ com redução de 1,3\% na média do grupo experimental. As médias do grupo $\mathrm{GV}_{127}$ reduziram $25,29 \%$, os animais do grupo $\mathrm{GV}_{40}$ tiveram média reduzida em $12,17 \%$.

Ao mesmo tempo em que se observou aumento do diâmetro do lúmen dos túbulos seminíferos, os animais dos grupos experimentais de 40 e 127 dias apresentaram reduções das médias dos eixos menores dos túbulos seminíferos, ou seja, o espaço que deveria ser ocupado por células da linhagem germinativa foi reduzido em duas frontes, eixo maior (diâmetro) e eixo menor do túbulo seminífero. Internamente ocorreu aumento do lúmen tubular decorrente da diminuição da celularidade do epitélio seminífero. Externamente a redução do eixo maior (diâmetro tubular) e do eixo menor dos túbulos seminíferos deflagram a atrofia dos túbulos seminíferos em decorrência da ação deletéria da droga (Vaisheva et al. 2007, Nasrabadi et al. 2012).

A área total do túbulo seminífero no grupo $\mathrm{GV}_{127}$ reduziu $41,20 \%$, os animais do grupo $\mathrm{GV}_{64}$ obtiveram média $5,37 \%$ menor, já os animais do grupo $\mathrm{GV}_{40}$ apresentaram média $23,72 \%$ menor que o grupo controle de mesma idade.

As reduções observadas nos grupos experimentais de $40\left(\mathrm{GV}_{40}\right)$ e $127\left(\mathrm{GV}_{127}\right)$ dias foram muito significativas $(\mathrm{p} \leq 0,01)$, enquanto que os animais do grupo $\mathrm{GV}_{64}$ apresentaram média com redução significativa $(\mathrm{p} \leq 0,05)$.

A área do lúmen tubular apresentou-se aumentada nos grupos experimentais $\mathrm{GV}_{64}$ e $\mathrm{GV}_{127}$ sendo as diferenças muito significativas $(\mathrm{p} \leq 0,01)$. Já os grupos $\mathrm{GC}_{40} \mathrm{e} \mathrm{GV}_{40}$ não apresentaram diferenças $(p>0,05)$ quando comparados entre si, demonstrando aumento de $11,18 \%$ na média do grupo $\mathrm{GV}_{40}$. As médias do grupo $\mathrm{GV}_{127}$ foram $39,63 \%$ maiores que o grupo controle, no grupo $\mathrm{GV}_{64}$ as médias foram $41,21 \%$ maiores.

A área do epitélio seminífero mostrou se reduzida em todos os grupos experimentais $\left(\mathrm{GV}_{127}, \mathrm{GV}_{64}\right.$ e $\left.\mathrm{GV}_{40}\right)$. As reduções foram classificadas como muito significativas $(p \leq 0,01)$ em todas as idades estudadas $(40,64$ e 127 dias). A média da área do epitélio seminífero do grupo $\mathrm{GV}_{127}$ foi 59,67\% menor, os animais do grupo $\mathrm{GV}_{64}$ tiveram médias $16,99 \%$ menor que a média do grupo $\mathrm{GC}_{64}$, já os animais do grupo $\mathrm{GV}_{40}$ apresentaram médias $27,67 \%$ menores que as médias dos animais do grupo $\mathrm{GC}_{40}$.

Uma das metas estabelecidas nesse estudo foi de quantificar as frequências dos principais tipos celulares do epitélio seminífero (Quadro 4), com o objetivo de avaliar as influências causadas pelo sulfato de vincristine sobre a população celular.

Os grupos controles $\left(\mathrm{GC}_{40}, \mathrm{GC}_{64}\right.$ e $\left.\mathrm{GC}_{127}\right)$ apresentaram características morfológicas normais (Fig.1A1-C1). As associações celulares da linhagem germinativa, caracterizando os estágios do ciclo do epitélio seminífero estavam bem definidas, sem alterações celulares evidentes.

Houve uma redução muito significativa $(\mathrm{p} \leq 0,01)$ na frequência dos túbulos seminíferos contendo espermatogônias do tipo A em todos os grupos tratados com sulfato de vincristine. Não houve indícios de recuperação do epitélio seminífero à longo prazo (127 dias), sugerindo um possível dano permanente e de caráter irreversível. 

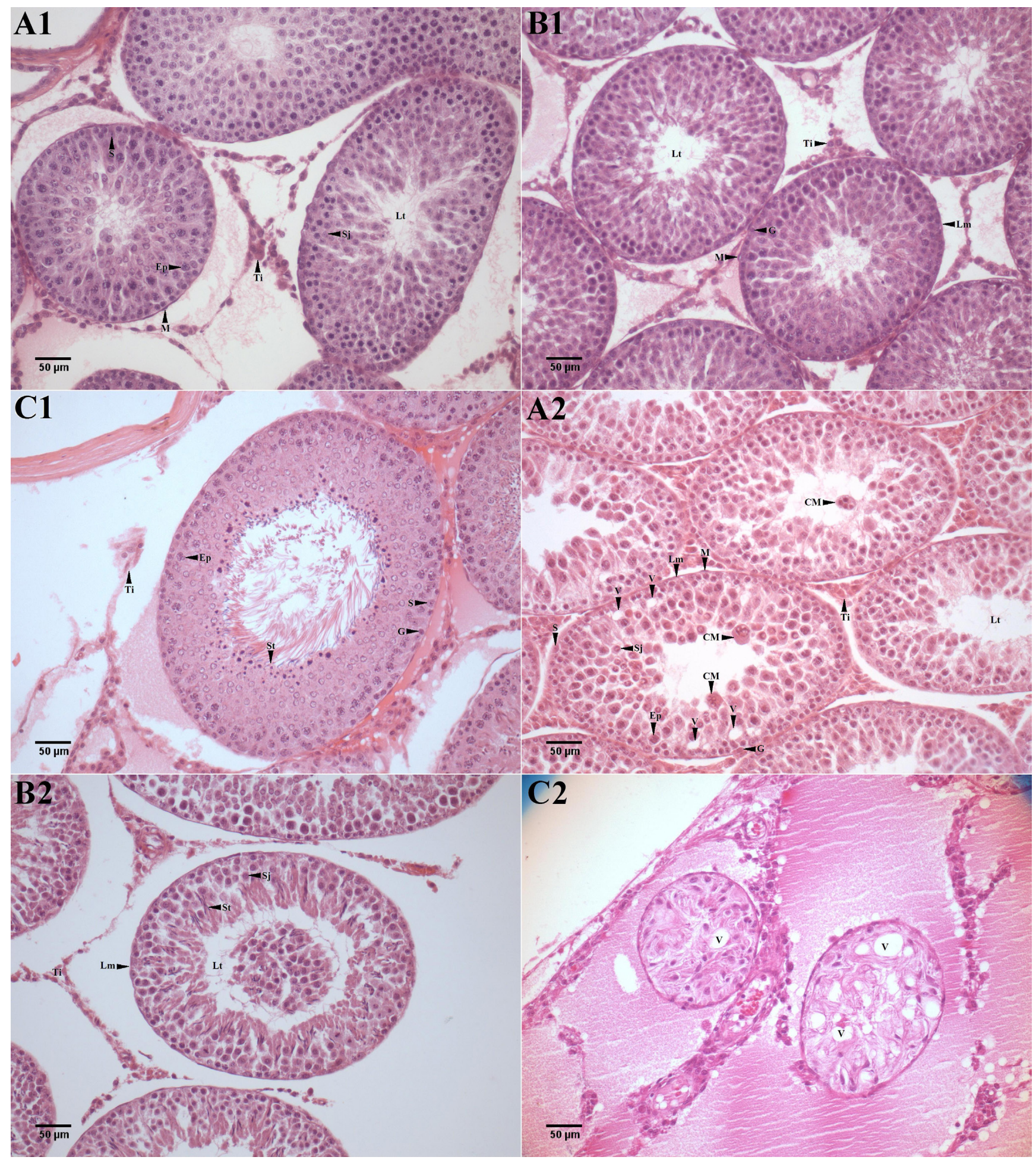

Fig.1. (A1) Seções tubulares dos testículos de ratos albinos do grupo controle e sacrificados aos 40 dias de vida (GC ${ }_{40}$ ). HE, obj.20x. (B1) Seções tubulares dos testículos de ratos albinos do grupo controle e sacrificados aos 64 dias de vida (GC ${ }_{64}$ ). HE, obj.20x. (C1) Fotomicrografia de seções tubulares dos testículos de ratos albinos do grupo controle e sacrificados aos 127 dias de vida (GC ${ }_{127}$ ). HE, obj.20x. (A2) Seções tubulares dos testículos de ratos albinos tratados com sulfato de vincristine e sacrificados aos 40 dias de vida $\left(\mathrm{GV}_{40}\right)$. Observam-se efeitos deletérios no epitélio seminífero. HE, obj.20x. (B2) Seções tubulares dos testículos de ratos albinos tratados com sulfato de vincristine e sacrificados aos 64 dias de vida $\left(\mathrm{GV}_{64}\right)$. Observam-se restos celulares oriundos da descamação do epitélio seminífero. HE, obj.20x. (C2) Seções tubulares dos testículos de ratos albinos tratados com sulfato de vincristine e sacrificados aos 127 dias de vida $\left(\mathrm{GV}_{127}\right)$. Evidencia-se degeneração severa dos túbulos seminíferos, desorganização e vacuolizações do epitélio seminífero. HE, obj.20x. Célula mióide (M), lúmen tubular (Lt), tecido intersticial (Ti), espermatogônia (G), lâmina limitante (Lm), núcleo da célula de Sertoli (S), espermatócito primário (Ep), espermátide jovem (Sj), espermátide tardia (St), vacuolização (V), célula multinucleada (CM). 
Quadro 4. Valores percentuais médios das frequências dos tipos celulares espermatogônia A (GA), espermatogônia B e intermediária (GBI), espermatócito primário (EP), espermátide jovem (SJ), espermátide tardia (ST) e células de Sertoli (S) e desvio padrão ( \pm DP) nos túbulos seminíferos em grupos de ratos albinos controles (GC) e tratados (GV) de 40, 64 e 127 dias de idade $\left(\mathrm{GC}_{40}, \mathrm{GV}_{40}, \mathrm{GC}_{64}, \mathrm{GV}_{64}, \mathrm{GC}_{127}\right.$ e $\left.\mathrm{GV}_{127}\right)$

\begin{tabular}{|c|c|c|c|c|c|c|c|c|c|c|c|c|}
\hline \multicolumn{13}{|c|}{ Grupos } \\
\hline Tipos celulares (\%) & $\mathrm{GC}_{127}$ & $\pm \mathrm{DP}$ & $\mathrm{GV}_{127}$ & $\pm \mathrm{DP}$ & $\mathrm{GC}_{64}$ & $\pm \mathrm{DP}$ & $\mathrm{GV}_{64}$ & $\pm \mathrm{DP}$ & $\mathrm{GC}_{40}$ & $\pm \mathrm{DP}$ & $\mathrm{GV}_{40}$ & $\pm \mathrm{DP}$ \\
\hline GA & $97,4 a^{*}$ & 2,3 & $46,05 b^{*}$ & 5,3 & 93a* & 3,7 & $76,8 b^{*}$ & 4,3 & $74,8 a^{*}$ & 4,1 & $60,2 b^{*}$ & 6,8 \\
\hline GBI & $71,07 a^{*}$ & 2,6 & $55,7 b^{*}$ & 3,9 & $54,25 a$ & 3,3 & $52,55 a$ & 3,3 & $44,1 \mathrm{a}$ & 4 & $41,95 a$ & 3,1 \\
\hline SJ & $100 a^{*}$ & 0 & $40,4 b^{*}$ & 3,5 & $95,55 \mathrm{a}$ & 3,5 & $94,15 a$ & 3,3 & $66,25 a$ & 3,2 & $66,3 \mathrm{a}$ & 3,2 \\
\hline ST & $100 a^{*}$ & 0 & $39,3 b^{*}$ & 2,9 & $98,85 a^{*}$ & 0,3 & $74,7 b^{*}$ & 3,7 & $54,45 a$ & 2,8 & $54,65 a$ & 2,8 \\
\hline
\end{tabular}

Letras diferentes = médias diferiram entre si pelo teste " $U$ " de Mann-Whitney $(p \leq 0,05)$; Letras diferentes com "* " médias diferiram entre si pelo teste "U" de Mann-Whitney $(\mathrm{p} \leq 0,01)$; Letras iguais = médias não diferiram entre si pelo teste "U" de Mann-Whitney $(p>0,05)$.

Os resultados desse trabalho corroboram em parte com os estudos realizados por Joshi \& Ambaye (1968), que estudou os efeitos do extrato de vinca rosea sobre os testículos de ratos. A pesquisa descreve danos às células da linhagem germinativa, principalmente espermatogônias indiferenciadas do tipo A, sendo esse um dos tipos celulares mais danificados pelo quimioterápico.

Em relação aos animais tratados, as espermatogônias diferenciadas tipo B e intermediária revelaram frequência reduzida no grupo tratado de 127 dias de vida, e essa redução foi considerada muito significativa $(\mathrm{p} \leq 0,01)$.

Nesse estudo, a frequência dos espermatócitos primários em túbulos seminíferos foi estatisticamente menor no grupo tratado de 127 dias de idade $\left(\mathrm{GV}_{127}\right)$, sendo essas reduções muito significativas $(p \leq 0,01)$. Os demais grupos experimentais não apresentaram diferenças significativas $(p>0,05)$.

Em relação às espermátides jovens verificou-se reduções muito significativas $(p \leq 0,01)$ nos animais do grupo $\mathrm{GV}_{127}$. Não foram observadas diferenças $(p>0,05)$ nos grupos $\mathrm{GV}_{40}$ e $\mathrm{GV}_{64}$ quando comparados aos respectivos controles.

As médias dos túbulos seminíferos com espermátides tardias acompanharam comportamento semelhante ao observado com a variável espermátides jovens. Não houve diferenças relevantes ( $>00,05)$ entre o grupo $\mathrm{GV}_{40}$ quando comparado ao controle de mesma idade, em contrapartida, os grupos $\mathrm{GV}_{64}$ e $\mathrm{GV}_{127}$ revelaram diferenças muito significativas $(\mathrm{p} \leq 0,01)$.

As médias dos túbulos seminíferos com células de Sertoli não apresentaram alterações $(\mathrm{p}>0,05)$ nos grupos $\mathrm{GV}_{40} \mathrm{e}$ $\mathrm{GV}_{64}$, porém, o grupo tratado $\mathrm{GV}_{127}$ demonstrou diferenças altamente significativas $(\mathrm{p} \leq 0,01)$.

Segundo Parvinen et al. (1978), ratos tratados com altas doses de sulfato de vincristine podem apresentar destruição das células de Sertoli através de depleção dos seus microtúbulos e mitocôndrias. Além disso, observou-se uma paralisação dos processos de divisão celular (mitose e meiose) seguida de morte das células da linhagem germinativa.

Formações multinucleadas (Fig.1A2) oriundas de espermátides jovens, descamação do epitélio seminífero com presença de restos celulares e de células da linhagem germinativa no lúmen dos túbulos seminíferos e vacuolizações foram alterações morfológicas comumente observadas nos testículos dos animais dos grupos tratados.

Aglomerados de células germinativas e de restos celulares no lúmen dos túbulos seminíferos originam-se do processo de descamação do epitélio seminífero. Tal descamação provêm da ação citotóxica de sulfato de vincristine sobre as células do epitélio seminífero. Nesse estudo, descamação do epitélio seminífero foi observada nos animais do grupo tratado, principalmente 0 grupo $\mathrm{GV}_{64} \cdot \mathrm{Os}$ animais do grupo GV127 apresentaram danos severos ao epitélio seminífero (Fig.1C2).

Diversos estudos constataram a ocorrência de células gigantes, vacuolizações e descamação de células do epitélio seminífero (Fig.1B2) em testículos de ratos tratados com agentes antineoplásicos quimioterápicos (Daleck et al. 1995, Nolte et al. 1995, Cabral et al. 1997, Vendramini et al. 2010, Vendramini et al. 2012).

\section{CONCLUSÃO}

O sulfato de vincristine apresenta citotoxicidade para o epitélio seminífero, alterando parâmetros morfométricos, estereológicos e histológicos do testículo. Os efeitos estão intimamente relacionados com o estágio reprodutivo em que se efetua a avaliação.

\section{REFERÊNCIAS}

Bordallo M.A.N., Guimarães M.M., Carriço M.K. \& Dobbin J. 2001. Função gonadal de sobreviventes de doença de Hodgkin tratados na infância e adolescência com quimioterapia. Arq. Bras. Endocrinol. Metabol. 45(1):8795. http://dx.doi.org/10.1590/S0004-27302001000100012.

Brilhante O., Okada F.K., Sasso-Cerri E., Stumpp T. \& Miraglia S.M. 2012. Late morfofunctional alterations of the Sertoli cell caused by doxorubicin administered to prepubertal rats. Revta Reprod. Biol. Endocrinol. 10:1-16. PMid:22967030.

Cabral B.M.G., Hayashi H. \& Miraglia S.M. 1997. Histomorphometry of sexually immature albino rat testis after x ray-irradiation. Interciencia 22:71-80.

Clegg E.J. 1960. The age at which male rats become fertile. J. Reprod. Fertil. 1:119-120.

Daleck C.R., Franceschini P.H., Padilha Filho J.G., Alessi A.C., Garcia J.M., Martins M.I.M. \& Costa Neto J.M. 1995. Alterações produzidas a nível de testículo e sêmen de cães submetidos à administração de sulfato de vincristina. Braz. J. Vet. Res. Anim. Sci. 32(1):51-56. http://dx.doi.org/10.11606/ issn.1678-4456.bjvras.1994.52090.

Delbès G., Vaisheva F., Luu T., Marcon L., Hales B.F. \& Robaire B. 2010. Reversibility of the effects of the chemotherapeutic regimen for non-Hodgkin lymphoma, cyclophosphamide, doxorubicin, vincristine, and prednisone, on the male rat reproductive system and progeny outcome. Reprod. Toxicol. 29(3):332338. http://dx.doi.org/10.1016/j.reprotox.2010.01.007. PMid:20096776. 
Diniz P.P.V.P., Camacho A.A., Santana A.E., Sobreira M.F.R. \& Velasque F.G. 1999 Eletrocardiografia e avaliação das enzimas musculares em cães tratados com sulfato de vincristina. Ars Vet. 15:170-176.

Eboetse Y.O., Ifeanyi A.C., Adewale O.S., Carmel N.C., Chai S.L. \& Olugbenga O.A. 2011. Three-dimensional quantitative analysis of testicular tissue sections of sprague-dawley rat: the after treatment responses to varying doses of Momordica charantia. Agricult. Biol. J. N. Am. 2(11):1390-1394. http://dx.doi.org/10.5251/abjna.2011.2.11.1390.1394.

Gundersen H.J.G., Bendtsen T.F., Korbo L., Marcussen N., Møller A., Nielsen K., Nyengaard J.R., Pakkenberg B., Sørensen F.B., Vesterby A. \& West M.J. 1988. Some new, simple and efficient stereological methods and their use in pathological research and diagnosis. Acta Pathol. Microbiol. Immunol. Scand. 96(5):379-394. http://dx.doi.org/10.1111/j.1699-0463.1988. tb05320.x. PMid:3288247.

Hacker-Klom U.B., Meistrich M.L. \& Gohde W. 1986. Effect of doxorubicin and 4 -epi-doxorrubicin on mouse spermatogenesis. Mutat. Res. 160(1):39-46. http://dx.doi.org/10.1016/S0027-5107(96)90007-X. PMid:3456485.

Hodel C., Ettlin R.A. \& Zschauer A. 1984. Morphological changes produced in rat testis by anticancer drugs: review of metabolism and reproduction in the toxic response to drugs and other chemicals. Arch. Toxicol. 7:147-150.

Howell S.J. \& Shalet S.M. 2001. Testicular function following chemotherapy. Human Reprod. Update 7(4):363-369. http://dx.doi.org/10.1093/ humupd/7.4.363. PMid:11476348.

Joshi M.S. \& Ambaye R.Y. 1968. Effect of alkaloids from vinca rosea l.on spermatogenesis in male rats. J. Exp. Biol. 6(4):256-257. PMid:5720688.

Leblond C.P. \& Clermont Y. 1952. Definition of the stages of the cycle of the seminiferous epithelium in the rat. Annals N.Y. Acad. Sci. 55(4):548-573. http://dx.doi.org/10.1111/j.1749-6632.1952.tb26576.x. PMid:13139144.

Mandarim-De-Lacerda C.A. 1995. Métodos quantitativos em morfologia. Editora UERJ, Rio de Janeiro. 131p.

Martins D.B., Lopes S.T.A., Mazanti C.M., Spanevello R., Schmatz R., Corrêa M., Stefanello N., Schetinger M.R., Morsch V. \& Veiga A.P.M. 2011. Lipid peroxidation in rats treated with vincristine sulphate and nandrolone decanoate. Arq. Bras. Med. Vet. Zootec. 63(1):107-113. http://dx.doi. org/10.1590/S0102-09352011000100017.

Michalany J. 1998. Técnica Histológica em Anatomia Patológica: com instruções para o $1^{\circ}$ cirurgião, enfermeiras e citotécnico. $3^{\underline{a}}$ ed. Michalany, São Paulo, SP. 295p.

Miraglia S.M. \& Hayashi H. 1993. Histomorpometry of immature rat testis after heating. J. Morphol. 217(1):65-74. http://dx.doi.org/10.1002/ jmor.1052170106. PMid:8411187.
Moura C.S., Guerra M.M.P., Silva Júnior V.A., Silva C.G.C., Caju F.M. \& Alves L.C. 2006. Avaliação histomorfométrica do parênquima testicular de ratos adultos tratados com diferentes doses de ivermectina. Arq. Bras. Med. Vet. Zootec. 58(5):799-808. http://dx.doi.org/10.1590/S0102-09352006000500015.

Nak D., Nay Y., Cangul I.T. \& Tuna B. 2005. A clinical-pathological study on the effect of vincristine on transmissible venereal tumour in dogs. J. Vet. Med. 52(7):366-370. http://dx.doi.org/10.1111/j.1439-0442.2005.00743.x. PMid:16109105.

Nasrabadi T.H., Mohammadnejad D. \& Nikpour F. 2012. Protective role of GNRH antagonist (cetrorelix) on side effect of vincristine on diameter of seminiferous tubules of mice. Int. J. Fertil. Steril. 6(1):75-75.

Nolte T., Harleman J.H. \& Jahn W. 1995. Histopathology of chemically induced testicular atrophy in rats. Exp. Toxicol. Pathol. 47(4):267-286. http://dx.doi. org/10.1016/S0940-2993(11)80260-5. PMid:8855122.

Parvinen L.-M., Söderström K.-O. \& Parvinen M. 1978. Early effects of vinblastine and vincristine on the rat spermatogenesis: analyses by a new transilluminationphase contrast microscopic method. Exp. Pathol., Jena 15(2):85-96. http:// dx.doi.org/10.1016/S0014-4908(78)80072-6. PMid:354959.

Rosenthal R.C. 1981. Clinical applications of vinca alkaloids. J. Am. Vet. Med. Assoc. 179(11):1084-1086, 1086. PMid:6948802.

Russell L.D. \& França L.R. 1995. Building a testis. Tissue Cell 27(2):129-147. http://dx.doi.org/10.1016/S0040-8166(95)80016-6. PMid:7778091.

Russell L.D., Ettlin R.A., Sinhahikim A.P. \& Clegg E.D. 1990. The classification and timing of spermatogenesis, p.41-58. In: Ibid. (Eds), Histological and Histopathological: evaluation of the testis. Vol.1. Cache River Press, USA.

Scherle W. 1970. A simple method for volumetry of organs in quantitative stereology. Mikroskopie 26(1):57-63. PMid:5530651.

Vaisheva F., Delbès G., Hales B.F. \& Robaire B. 2007. Effects of the chemotherapeutic agents for non-Hodgkin lymphoma, cyclophosphamide, doxorubicin, vincristine, and prednisone (chop), on the male rat reproductive system and progeny outcome. J. Androl. 28(4):578-587. http://dx.doi.org/10.2164/ jandrol.106.002428. PMid:17409468.

Vendramini V., Sasso-Cerri E. \& Miraglia S.M. 2010. Amifostine reduces the seminiferous epithelium damage in doxorubicin-treated prepubertal rats without improving the fertility status. Reprod. Biol. Endocrinol. 8(1):1-13. http://dx.doi.org/10.1186/1477-7827-8-3. PMid:20064221.

Vendramini V., Robaire B. \& Miraglia S.M. 2012. Amifostine-doxorubicin association causes long-term prepubertalspermatogonia DNA damage and earlydevelopmental arrest. Human Reprod. 27(8):2457-2466. http:// dx.doi.org/10.1093/humrep/des159. PMid:22593430. 